\title{
O uso das pegadas hídricas na agricultura do Brasil
}

\author{
The use of water footprints in agriculture of Northeast of Brazil \\ El uso de huellas de agua en la agricultura del Nordeste de Brasil
}

Recebido: 17/01/2021 | Revisado: 19/01/2021 |Aceito: 23/01/2021 | Publicado: 30/01/2021

\author{
Navilta Veras do Nascimento \\ ORCID: https://orcid.org/0000-0002-2181-4551 \\ Faculdade Luciano Feijão, Brasil \\ E-mail: naviltaveras@gmail.com \\ Sarah Monteiro Galdino \\ ORCID: https://orcid.org/0000-0003-2839-995X \\ Faculdade Luciano Feijão, Brasil \\ E-mail: sarah2mont@gmail.com \\ Teresa Lenice Nogueira da Gama Mota \\ ORCID: https://orcid.org/0000-0002-8911-1019 \\ Faculdade Luciano Feijão, Brasil \\ E-mail: teresa_mota@yahoo.com \\ José Levi Chaves de Sousa \\ ORCID: https://orcid.org/0000-0003-2174-1863 \\ Faculdade Luciano Feijão, Brasil \\ E-mail: levichaves1@hotmail.com \\ Rochelly Sousa Machado \\ ORCID: https://orcid.org/0000-0003-3985-011X \\ Faculdade Luciano Feijão, Brasil \\ E-mail: machadorochely@gmail.com
}

\begin{abstract}
Resumo
A água é um dos recursos bastante empregados na agricultura, e esta é responsável pelo consumo de mais de $72 \%$ de toda a água utilizada no país, é válido ressaltar que com o tempo as crises hídricas foram piorando e regiões como o Nordeste foram bastante afetadas pela seca, por isso, tornou-se cada vez mais imprescindível a necessidade de novos métodos de redução de desperdício de água. Tendo isso em vista, o presente artigo tem como principal propósito evidenciar a importância da Pegada Hídrica, seguindo estudos de revisões para a agricultura nordestina, o presente artigo apresenta a Pegada Hídrica como uma das soluções para a redução do desperdício de água doméstica, no setor industrial e agrícola, visando diminuir os futuros impactos causados pela falta de água mundial. Portanto, é indispensável a utilização de novas técnicas atinentes a melhor utilização da água para o melhoramento de sua produção agrícola.
\end{abstract}

Palavras-chave: Sustentabilidade; Agrícola; Água consumida.

\begin{abstract}
Water is one of the resources widely used in agriculture, and this is responsible for the consumption of more than $72 \%$ of all the water used in the country, it is valid to notice that over time the water crises were getting worse and regions such as the Northeast were quite affected by drought, so it has become increasingly imperative the need for new methods to reduce water waste. Regarding it, this article has as its main purpose to emphasize the importance of Water Footprint, following studies of revisions to the northeastern farming, this article presents the Water Footprint as one of the solutions for the reduction of waste of domestic water, industrial and agricultural sector, in order to reduce future impacts caused by lack of water. Therefore, it is essential to the use of new techniques linked to better to utilization of water for upgrade in agricultural production.
\end{abstract}

Keywords: Sustainability; Agricultural; Water consumed.

\section{Resumen}

El agua es uno de los recursos más utilizados en la agricultura, y es responsable del consumo de más del $72 \%$ de toda el agua utilizada en el país, cabe señalar que con el tiempo las crisis hídricas se han agravado y regiones como el Nordeste se han visto muy afectadas. sequía, por lo que la necesidad de nuevos métodos para reducir el desperdicio de agua se ha vuelto cada vez más esencial. Teniendo esto en cuenta, el objetivo principal de este artículo es resaltar la importancia de la Huella Hídrica, luego de estudios de revisión para la agricultura del noreste, este artículo presenta la Huella Hídrica como una de las soluciones para la reducción del desperdicio de agua doméstica en el sector. industrial y agrícola, con el objetivo de reducir los impactos futuros causados por la falta de agua en todo el mundo. Por tanto, es fundamental utilizar nuevas técnicas de mejor aprovechamiento del agua para mejorar la producción agrícola.

Palabras clave: Sostenibilidad; Agricultura; Agua consumida. 


\section{Introdução}

A água é um bem natural muito importante para os seres humanos, ela cobre $75 \%$ da superfície do planeta e é formada em sua maioria por mares e oceanos, porém apenas 3\% de toda a água doce é potável, ou seja, reúne as condições mínimas para o uso da água pelas pessoas. Essa água é utilizada para atividades muito importantes no cotidiano das pessoas e também é empregada nas atividades industriais e agrícolas, que são atividades indispensáveis para a economia do nosso país (Decinino, 2007).

Vários especialistas da área como Barreto e Shiklomanov (2018) afirmam que daqui há algumas décadas irá ocorrer um colapso de água potável, pois o seu ciclo continuará o mesmo, entretanto a procura pela água somente irá aumentar ao longo dos anos e para agravar ainda mais a situação a interferência do homem no meio ambiente com a poluição e desperdício da água tornaram-se problemas comuns na sociedade contemporânea.

Então, prevendo essa situação, estudiosos têm proposto diversas práticas para a diminuição do consumo de água, principalmente na agricultura que é um dos setores que mais consome água no Brasil, e foi a partir disso que surgiu a pegada hídrica, que teve a sua definição elaborada por Arjen Hoekstra (2002) citado por Hoesktra e Chapagain (2007), e ela serve como um indicador de todo o consumo de água por pessoas e todos os tipos de produtos. A pegada hídrica se resume basicamente no cálculo de todo o volume de água utilizado para produzir determinados bens e serviços, além disso, ela calcula tanto o consumo direto quanto o indireto.

Este artigo procura evidenciar a Pegada Hídrica como um fator determinante na diminuição do consumo de água, além de apresentar a importância de sua utilização no setor agrícola nordestino que necessita de menos utilização de água e um maior desenvolvimento na produção de seus produtos.

\section{Metodologia}

Esse trabalho prioriza bibliografias revisadas, as quais justificam e discutem o tema visto em referências expostas ao mundo científico como: artigos de revisão e técnicos, periódicos e sites. Nessa contextualização, melhora os conhecimentos vistos nas revisões anteriores e criticar alguns pontos, diante de uma problemática, da pegada hídrica mundial e principalmente no semiárido nordestino. É válido destacar importantes questões como no tocante a água para consumo, alimentos e outros aspectos indispensáveis dentro de cada comunidade, municípios, estados, países onde são exploradas.

$\mathrm{Na}$ contribuição de aprofundamento e compreensão para inovar um determinado tema, numa conclusão com resultados satisfatórios, deve usar técnicas de estudo e metodologia científica da pegada hídrica no manual de Water Footprint Network (Hoekstra et al., 2009). Os cálculos da Water Footprint envolvem a soma de três etapas: cultivo (água verde, que vem da chuva); modelagem de matérias-primas e ingredientes (água azul, retirada de rios e mananciais) e volume necessário para diluir poluentes do processo produtivo ou fabricar embalagens (água cinza) - caso da indústria de refrigerantes, classificada como hidro-intensiva.

A maior parte dos usos de água ocorre na produção agrícola ressaltando também um número significativo de volume de água consumida e poluída nos setores industriais e domésticos (Silva et al., 2013). É curioso destrinchar o perfil de cada região quanto ao consumo de água, por este motivo, a PH, sigla que doravante usaremos neste trabalho para nos referirmos a Pegada Hídrica é formada por três componentes: o verde, o azul e o cinza:

PH verde - relaciona-se, ao consumo de água das chuvas, sendo a maior parte consumida na produção agrícola;

PH azul - água da superfície e do solo, por exemplo, obtida de poços, processos industriais que produzem vapor ou na incorporada nos produtos; 
PH cinza - determinado como o volume de água doce que é necessária para apropriar-se a carga de poluentes existentes com base em padrões de qualidade de água no ambiente; o estudo divulgado por Hoekstra \& Mekonnen (2012) também apresenta a PH distribuído entre estes três componentes (Figura 1).

Figura 1. As pegadas hídricas verde, azul e cinza para as nações no período de 1996-2005. Os dados são apresentados em milímetros por ano.

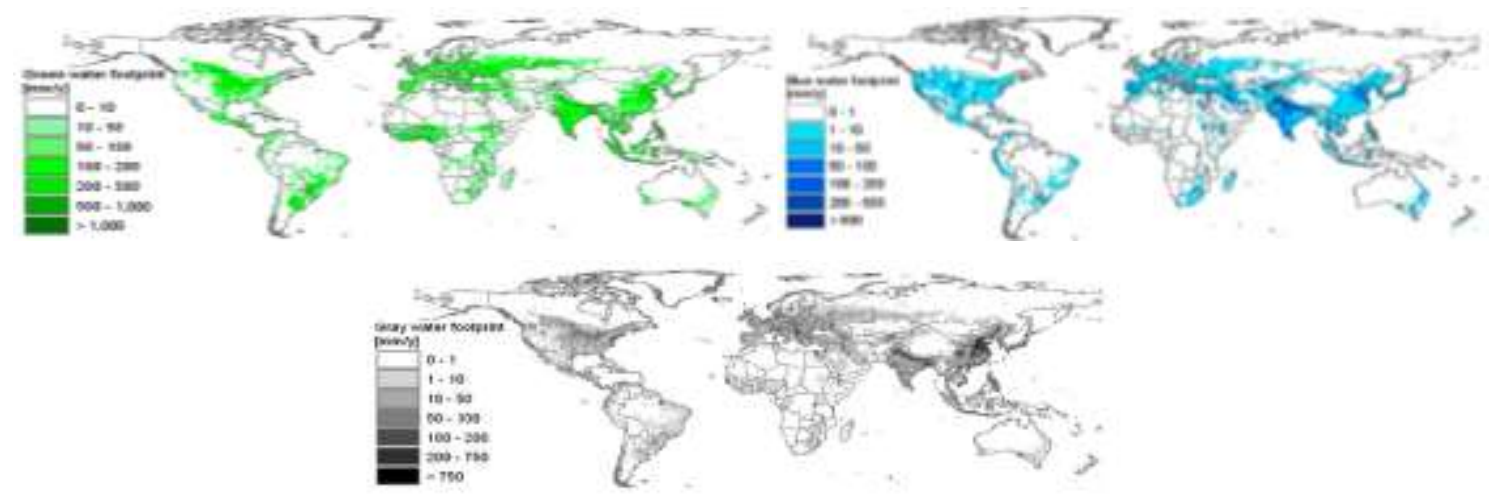

Fonte: Hoekstra e Mekonnen (2012).

No caso do Brasil, fica comprovado que os componentes da $\mathrm{PH}$ respondem propriamente à densidade populacional, neste sentido, cabe destacar que há grande PH na região Sul e Sudeste do país. No caso da PH verde, pode-se ressaltar a região Centro-Oeste, que apesar de menos populosa, apresenta grandes extensões de área agrícolas. A PH azul é maior no Sul e Sudeste, áreas com maior concentração de indústrias, e na região Nordeste, sobretudo em áreas com poços para obtenção de água do subsolo. No caso da PH cinza, as maiores são nas regiões mais densas do Sudeste, contudo este componente da PH é o mais disseminado no território nacional, sendo então, uma assinalação da necessidade de maiores cuidados com os recursos hídricos, por exemplo, com o aumento no tratamento de esgoto.

A metodologia adotada para pegada hídrica, ajuda melhorar o resumo, apresentado em todo um conceito, de como fazer para multiplicar o uso dessa água potável nos produtos. Sendo assim, considera-se primordialmente a origem das características globais de água potável em quantidade e no que se gasta. A distribuição de água doce em todo o planeta é questão de vida para a humanidade. Desperta o interesse para uma sustentabilidade ambiental e hídrica para uso de uma ferramenta técnica chamada pegada hídrica e tornar consciente que será uma lição de aprendizado para sociedade.

\section{Resultados e Discussão}

\subsection{Pegada Hídrica}

No Nordeste, onde há muitas regiões áridas e semiáridas, ainda passamos por longos períodos de redução de chuvas. Assim, contamos com mais uma tribulação na região agrícola, o crescimento da população e a péssima gestão do consumo da água são problemas assinalados, desse modo (Marengo et al., 2011). O presente artigo também analisou a água como fator limitante para a produção agrícola na Bacia do Forquilha, localizada no município de Quixeramobim, no Ceará, segundo diferentes cenários climáticos, verificando-se o uso e a disponibilidade hídrica como um dos elementos essenciais ao desenvolvimento sustentável da agricultura familiar no semiárido nordestino. (Soares et al., 2013).

A definição de pegada hídrica está diretamente relacionada com o conceito de água virtual, que foi introduzido por Allan (Allan, 1993 citado por Hoesktra \& Chapagain, 2007), que discorre a respeito da quantidade necessária de água para 
produzir um produto ou um serviço, e também levando em conta a verificação do comércio indireto de água que está incorporado em determinados produtos.

\section{Agricultura}

Os estudos de Hoekstra e Chapagain (2007) afirmam que o setor agrícola é responsável pela maior utilização de água doce, pois corresponde a $70 \%$ do consumo de água total do planeta, mas em contrapartida o volume de água gasto no setor industrial é de $22 \%$ e no uso doméstico é de $8 \%$. Então a dimensão da pegada hídrica mundial é delimitada pelo consumo de alimentos produzidos, a utilização de água na indústria e na atividade doméstica, sendo o consumo de água de $1.243 \mathrm{~m}^{3} /$ ano per capita por habitante (Hoekstra \& Chapagain, 2007). A pegada hídrica mundial do setor agrícola é de 6.390 x 109 m3/ano, a doméstica é de 344 x 109 m3/ano e a da indústria 716 x 109 m3/ano. Portanto, tendo em consideração os dados supracitados é possível inferir que o setor produtivo que mais utiliza a água é a agricultura irrigada.

Nos povoados da zona rural do Nordeste muitas atividades são desenvolvidas, nesse ambiente marcado por estiagens a água adquire importância ímpar, para tanto as comunidades rurais valem-se de economia e organização em relação ao uso e reuso da água. Existem algumas opções a serem analisadas, sobretudo no tocante as propriedades da água, a separação dela, o desperdício e o seu emprego de modo direto (Di Moura, 2014; Mendonça, 2015)

Pereira (2015) observou que a fruticultura irrigada no Ceará e no Rio Grande do Norte ocorre em terras produtivas e de excelente qualidade, entretanto, não há expectativas de crescimento social no âmbito em que estão imersas essas comunidades, a partir dessas observações Pereira (2015) questionou o modelo criado, também levantou pontos negativos acerca do capital armazenado, houve sim um acréscimo relevante, que no entanto não é satisfatório do ponto de vista econômico para as famílias das comunidades.

Rigotto et al. (2016) acerca das experiências no Ceará e Rio Grande do Norte destacam o desrespeito às regras de políticas democráticas a nível estatal, sendo que muitas práticas são controversas, experimentos em prol de toda a comunidade nem sempre tem o fito de beneficiar a comunidade, assim, muitas atitudes narcisistas e excludentes ocorrem no âmbito da agricultura irrigada não desenvolvendo plenamente aquela comunidade que muitas vezes não logra êxito.

Os Estados discutidos desenvolvem um agronegócio empreendedor e dinâmico na região Nordeste, possuem sistemas de irrigação modernizados que empregam, por exemplo, peças de kits modernos portátil e elétrico nos perímetros de irrigação, e há uma preocupação ambiental com a água doce e o solo. Também cabe destacar a tecnologia empregada pela Empraba (Empresa Brasileira de Pesquisa Agropecuária) que faz uma conexão com o comércio, facilitando assim a produção e as vendas nos portos e rodovias; de outro lado há os incentivos fiscais e a imunidade tributária para produtos agrotóxicos entre outros.

Rigotto et al. (2016) destacam uma postura excludente e que não é plenamente democrática em relação às políticas de promoção da agricultura irrigada do Ceará e Rio Grande do Norte por parte do Estado, se por um lado há implementos como a instalação dos perímetros de irrigação e política de incentivo ao agronegócio; por outro há um descaso em relação às comunidades, visto que há a necessidade de um estudo prévio a fim de verificar as necessidades da comunidade e como esta desenvolve suas atividades com água escassa, esses estudos devem levar em consideração os impactos socioambientais.

Em 2014, a Pesquisa Nacional por Amostra de Domicílios (PNAD) reuniu dados em áreas rurais residenciais em $34,5 \%$, onde esses pontos são ligados a redes com objetivos de abastecer com água ou sem interiorizar certa quantidade de canos.

A Secretária do Desenvolvimento Agrário do Estado do Ceará (DAS), subsidiada pelo Banco Mundial e Governo do Estado do Ceará, reconhece as atitudes do Projeto São José III (PSJ III) em relação aos sistemas de reuso de água. E trouxe, objetivo de progresso rural estável por um longo período de tempo, já no tocante às ações estratégicas dentro da política do 
Estado, a rotina de 70 familiares que compõem a comunidade foram impactadas pelo Projeto São José III, visto que a água é um recuso natural indispensável à vida no semiárido, assim o projeto supracitado compromete-se em orientar obras hídricas menores visando o desenvolvimento (Ceará, 2017).

\section{Sustentabilidade}

O desmatamento autorizado legalmente pelas mudanças propostas no Código Florestal, causará um efeito direto que pode prejudicar a quantidade e a qualidade de água disponível em um dos maiores conglomerados humanos do país (Padua et al., 2011).

Os problemas em relação ao emprego incorreto da água e o seu desperdício são agravados pelo desmatamento, levando em consideração os fenômenos climáticos alternados globais que provocam instabilidade climática, destarte, a falta de água é uma realidade, mesmo que vivamos em um país de recursos hídricos abundantes, nenhuma região está imune a problemas de abastecimento, muitos sujeitos acabam sendo condicionados a não aplicar medidas que lograrão êxito a longo prazo em relação ao uso e ao reuso da água, assim há alguns desafios que podem agravar a crise hídrica como o desmatamento de biomas como a caatinga, o manejo sem conhecimento técnico em relação ao bioma (Souza, Artigas \& Lima, 2015). Seguidamente cabe enfatizar os impactos advindos dos problemas e desafios infracitados, assim o semiárido da região nordestina tem mostrado fracassos por não implementar medidas socioambientais que visem um desenvolvimento sustentável, e também há problemas relacionados a instabilidade política que prejudicam as comunidades rurais.

A água tem sido reutilizada há muito tempo, mas mesmo depois de décadas o desperdício é uma triste realidade, países como os Estados Unidos e Israel por exemplo que possuem regiões áridas e semiáridas empregam sistemas de irrigação em suas culturas e esses países ditam os métodos e normas adotados por outros países, o método 31 de irrigação por exemplo, demonstra a qualidade da água e a partir daí é possível direcionar essa água para diferentes funções e fins. (ABES,2015).

\section{Considerações Finais}

Pela observação dos aspectos analisados percebemos que a água é de extrema importância para o desenvolvimento do nosso país, por esse motivo temos que tomar medidas necessárias para diminuir drasticamente o seu desperdício.

A pegada hídrica é um método muito útil na tentativa de reduzir o uso de água no setor agrícola, principalmente em regiões como o semiárido nordestino que historicamente é carente de recursos hídricos.

A região Nordeste brasileira sofre há anos com a falta de água decorrente da estiagem, desse modo a produção agrícola tem que trabalhar com o mínimo de água possível sem perder a qualidade do produto, portanto a Pegada Hídrica se faz de extrema importância na agricultura nordestina, pois com a sua utilização podemos perceber e corrigir qual etapa da produção está desperdiçando água.

O presente artigo possibilitou uma análise da Pegada Hídrica como uma das soluções para a redução do desperdício de água doméstica, industrial e principalmente a água utilizada no setor agrícola nordestino.

A pegada hídrica serve como um indicador de sustentabilidade, que é capaz de monitorar o impacto do gasto da água em cada produto que é gerado, com a sua ampla utilização vamos poder diminuir o consumo desregrado, e desnecessário em vários setores do Nordeste, visando um futuro melhor e mais sustentável para a agricultura brasileira.

\section{Agradecimentos}

Gostaria de externar a minha profunda gratidão a todos os que colaboraram para a construção deste artigo, em especial o trabalho ímpar e dedicado de Teresa Lenice Mota, José Levi Chaves, Rochelly Sousa 
Research, Society and Development, v. 10, n. 1, e53810112055, 2021

(CC BY 4.0) | ISSN 2525-3409 | DOI: http://dx.doi.org/10.33448/rsd-v10i1.12055

\section{Referências}

Allan, J. A. (1993). Fortunately, there are substitutes for water otherwise our hiydro political futures would be impossible. In: Priorities for water resources allocation and management, ODA, London, 13-16.

ABES - Associação Brasileira de Engenharia Sanitária e Ambiental. Reuso de água nas crises hídricas e oportunidades no Brasil (2015).

Barreto, S. Especialista Biólogo. https://www.google.com.br/amp/m.folha.uol.com.br/amp/cotidiano/2017/03/1868198-seguimos-no-limite-diz-especialistaem-crise-hidrica-sobre-represas-de-sp.shtml

Ceará. Secretaria de Desenvolvimento Agrário do Ceará (SDA). Projeto São José III (2017). https://www.sda.ce.gov.br

Decinino, R. (2018) Água potável: Apenas 3\% das águas são doces. educação.uol.com.br/disciplinas/geografia/agua potável- apenas-3das-aguassãodoces.

Di moura, C. A. (2017) Conflitos Pelo Uso da Água. Caderno Prudentino de Geografia. Presidente Prudente. 36, 81-105.

Conjuntura Recursos Hídrigos do Brasil (2017) http://www.snirh.gov.br/portal/snirh/centrais-de-conteudos/conjuntura-dos-recursos-hidricos/relatorioconjuntura-2017.pdf

Hoekstra, A., \& Chapagain, A. K. (2017). The water footprint of coffee and tea consumption in the Netherlands. http://www.sciencedirect.com/science/article/pii/S092180090700105X

Hoekstra, A. Y., Chapagain, A. K., Aldaya, M. M., \& Mekonnen, M. M. (2009). The water footprint manual: State of the art. Water Footprint Network, p.127.

Hoekstra, A. Y., Mekonnen, M. M., Chapagain, A. K., Mathews, R. E., \& Richter, B. D. Global Monthly Water Scarcity: Blue Water Footprints versus Blue Water Availability(2012). PLoS ONE, 7(2).

Hoesktra, A. Y., \& Chapagain, A. K. (2007). Water footprints of nations: Water use by people as a function of their consumption pattern. In Water Integrated Assessment of Water Resources and Global Change, 35-48. 10.1007/978-1-4020-5591-1_3.

Marengo, J. A., Alves, L. M., Beserra, E. A., \& Lacerda, F. (2011) F. Variabilidade e mudanças climáticas no semiárido brasileiro. Recursos hídricos em regiões áridas e semiáridas / editores, Salomão de Sousa Medeiros, Hans Raj Gheyi, Carlos de Oliveira Galvão, Vital Pedro da Silva Paz - Campina Grande, PB: Instituto Nacional do Semiárido, 385 - 422 p. ISBN 978-85-64265-01-1.

Ministério da Integração Nacional - Superintendência do Desenvolvimento do Nordeste (Sudene). Delimitação do Semiárido (2017). http://sudene.gov.br/planejamento-regional/delimitacao-do-semiarido.

Mendonça, M. R. (2015) As Transformações Espaciais no Campo e os Conflitos pelo Acesso a Terra e a Água: as novas territorialidades do agrohidronegócio em Goiás. Revista Pegada, 16, n. especial.

Pereira, G. R. Avaliação de políticas de desenvolvimento rural para o semiárido: o agronegócio da fruticultura irrigada e a agricultura familiar (2015). Revista de Geografia, Recife, 32(5).

Silva, V. P. R., Aleixo, D. O., Dantas neto, J., Maracajá, K. F. B., \& Araújo, L. E. (2013). Uma medida de sustentabilidade ambiental: Pegada hídrica. Revista Brasileira de Engenharia Agrícola e Ambiental. 17(1), 100-105.

Rigotto, R. M. et al. Perímetos irrigados e direitos violados no Ceará e Rio Grande do Norte: "por que a água chega e a gente tem que sair?" (2016). Revista Pegada, 17(2), 122-144,

Souza, B. I. F., Artigas, R. C., \& Lima, E. R. V. (2015). Caatinga e desertificação. Mercator, Fortaleza, 14(1), 131-150.

Shiklomanov, I. Geólogo do Instituto Hidrológico Estatal de São Petersburgo, Rússia (2018) https://www.google.com.br/amp/s/super.abril.com.br/ciencia/aera-da-falta-dagua/amp/

Soares, R. B., \& Campos, K. C. Revista de Política Agrícola, (2013). Ano XXII (3). 